\title{
Wind-Driven Dynamics of Beach-Cast Wrack in a Tide-Free System
}

\author{
Sven Hammann 1,2, Martin Zimmer ${ }^{1,3 *}$ \\ ${ }^{1}$ Christian-Albrechts-Universität zu Kiel, Zoologisches Institut, Kiel, Germany \\ ${ }^{2}$ Thünen-Institut für Seefischerei, Hamburg, Germany \\ ${ }^{3}$ Paris-Lodron-Universität Salzburg, FB Organismische Biologie, AG Ökologie, Biodiversität \& Evolution der Tiere, \\ Salzburg, Austria \\ Email: ${ }^{*}$ martin.zimmer@sbg.ac.at
}

Received 27 December 2013; revised 3 February 2014; accepted 24 February 2014

Copyright (C) 2014 by authors and Scientific Research Publishing Inc.

This work is licensed under the Creative Commons Attribution International License (CC BY). http://creativecommons.org/licenses/by/4.0/

(c) (i) Open Access

\begin{abstract}
Whereas wrack dynamics on tidally influenced beaches have been studied to some detail, essentially nothing is known about how drift lines in tide-free coastal systems vary in space and time. We provide evidence for high spatial and temporal dynamics of beach-cast wrack on a sand beach in the Western Baltic Sea. Over the course of one year, the amount of weekly deposited macrophyte wrack fluctuated from zero to $3000 \mathrm{~g} \cdot \mathrm{m}^{-1}$ shoreline. Wrack mostly accumulated just above the waterline. Part of the beach-cast wrack is frequently re-suspended into coastal water upon extreme high water level events, or wrack patches are translocated landwards by wind-driven changes in water level or along the shoreline by winds. Consequently, the deposited wrack does accumulate, but a steady-state of ca $400 \mathrm{~g} \cdot \mathrm{m}^{-1}$ builds up within 2 - 3 weeks. Eelgrass wrack buried in sand decomposed almost twice as fast as on top of the sand or re-suspended in water. Fragmentation of leaves promoted decomposition only when wrack remained on the sand surface. The spatial and temporal distribution of this valuable source of organic matter is unpredictable and depends on wind and wind-driven waves.
\end{abstract}

\section{Keywords}

Decomposition; Drift Line; Spatial Subsidy; Zostera marina

\section{Introduction}

The deposition of macrophyte wrack, detached thalli and blades of macro-algae and eelgrasses, ashore in distinct

${ }^{*}$ Corresponding author. 
drift lines that stretch along sand and gravel beaches is of major significance as food and/or habitat for invertebrates of a relatively unproductive supra-littoral zone, and has been increasingly studied during the last decades (see [1]-[7] and reference therein). Besides its ecological relevance, coastal communities engaged in touristic activities are increasingly concerned by growing amounts of wrack masses being deposited ashore (for the Baltic Sea: [8] [9]).

The value of wrack deposits as spatial subsidy to the supra-littoral zone and their macrofaunal utilization as food and habitat, but also their spatio-temporal dynamics, being of fundamental ecological but also of societal interest (see above), depend on the spatial distribution, amount and species composition of the wrack deposited [4] [5] [10]. To this end, [4] studied different beaches along the south-western coast of Vancouver Island (B.C., Canada) to demonstrate that tidal dynamics, exposure and sediment characteristics of the beach and buoyancy of macro-algal wrack interact in shaping wrack deposition processes. Thus, it is tempting to hypothesize that tidefree coastal systems exhibit much less marked dynamics of wrack deposition and removal than do tidally affected beaches, and may, hence, be more predictable — this seems particularly valuable for touristic areas, where remarkable effort may be invested in cleaning beaches off beach-cast wrack (although the value of the drift line as exploring ground and educational material for tourists and children is increasingly being recognized: [11]).

The decomposition of wrack deposits adds to their spatio-temporal dynamics ashore, in turn, being dependent on wrack characteristics, such as chemical composition and fragment size, on micro-climatic conditions and on biotic interactions (c.f. [5] [12]). Thus it is the combination of place of deposition—horizontally along the marine-terrestrial gradient; vertically in the substratum (c.f. [4])—and wrack fragmentation through abrasion on the beach substratum that requires understanding to be able to predict the fate of wrack deposits ashore.

In the present study, we test the hypothesis that beach-cast macrophyte wrack in a tide-free coastal system undergoes less temporal and spatial dynamics than in a tidal system (c.f., [4]) and hence remains in place at the upper intertidal zone until it is decomposed. More specifically, we monitor wrack and beach dynamics on a sand beach in the Western Baltic Sea over the course of one year in the field, and examine eelgrass decomposition under various environmental conditions in laboratory experiments.

\section{Material and Methods}

\subsection{Study site}

The study was conducted on a sand/gravel beach of the small nature reserve area Bottsand near Kiel, Germany (Figure 1; 54 $25^{\prime} 28.98^{\prime \prime} \mathrm{N}, 10^{\circ} 17^{\prime} 12.77 " \mathrm{E}$ ). In 1939, the first 15 ha had been declared for protection, but only in 1987 the protected area obtained its actual size of 91 ha. The area arose about 150 years ago from a fossil beach wall system near the coast of Schöneberg. By sand movements from near-shore areas, coastline-parallel transport and accretion it continuously grows westwards. This development was stopped in 1972 by a new mole at the harbor of Marina/Wendtorf. The bay bar caused a lagoon, here called Bodden. The surrounding dry grass areas, salt marshes and dunes are a very species-rich environment, which is used by numerous bird species as breeding and resting place.

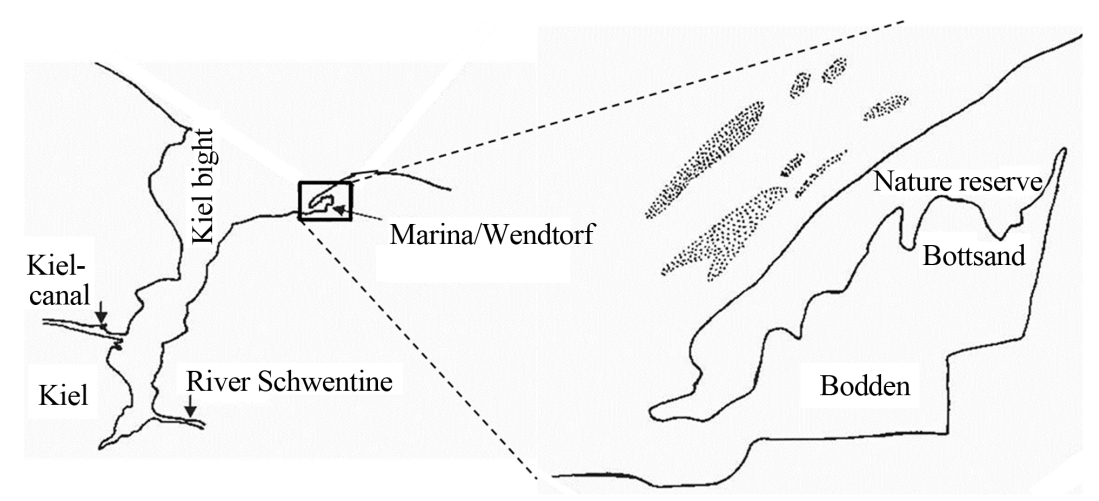

Figure 1. The nature reserve Bottsand near Kiel, Germany; dotted areas mark near-shore eelgrass beds in soft sediment. 
Situated in the Western Baltic Sea, the study area is essentially free of tidal influences. Thus, the only forces that can act on water-born drifting or beach-cast wrack are wind, wind-driven waves and near-shore currents. Since soft sediments prevail and hard-bottom communities are rare and only patchily distributed, primary production by eelgrass highly exceeds that by macroalgae (see also Results on contribution to total wrack masses).

\subsection{Detritus}

Beach-cast detritus was collected in different intervals from April 2005 to March 2006: weekly, monthly, and three-monthly. At each sampling date, the entire distance between the waterline and the dune was cleaned from detritus along a $50 \mathrm{~cm}$-wide transect. In the laboratory, the collected detritus was cleaned from sand and gravel, divided into five fractions-eelgrass (Zostera marina), brown algae (mostly Fucus vesiculosus), other algae, animal remnants, terrestrial plants-that were determined to the species or genus level (as far as possible) and weighed separately after having been oven-dried for one week at $60^{\circ} \mathrm{C}$.

\subsection{Water Levels}

Wooden poles placed at the seaward foot of the dunes were used to determine the water level at each sampling date in terms of beach width from the base of the dunes to the waterline. As the beach slope at Bottsand is quite shallow (1:150), relatively small changes in water levels can cause large changes in beach width.

\subsection{Weather Conditions}

Data on wind direction (deviation from N) and wind speed $\left(\mathrm{m} \cdot \mathrm{s}^{-1}\right)$, measured at the lighthouse of the Kiel bight every $8 \mathrm{~min}$, were obtained from GEOMAR (Kiel). Precipitation $\left[\mathrm{mm} \cdot \mathrm{m}^{-2} \cdot \mathrm{d}^{-1}\right]$ was measured directly at the study site through plastic beakers with a defined opening area that were buried in sand by half of their height and emptied at every sampling date.

\subsection{Wind Drift of Beach-Cast Wrack}

To get an impression of drifting direction of, and forces that act on, beach-cast wrack material, a $2.5 \times 2.5 \mathrm{~m}^{2}$ cage of chicken wire was positioned in north-south orientation at the center of the shore. 100 small plastic stripes with length and weight of typical Zostera marina blades were placed at the center of the cage. After one week, artificial Zostera marina blades were collected from the cage walls, and it was noted in which direction the material had been moved by the wind. This was repeated once a month over the entire sampling time.

\subsection{Wrack Decomposition}

To further understand the dependence of wrack decomposition, significantly contributing to spatio-temporal dynamics of wrack (c.f. [5]), on wrack fragment size and its position on the beach, mass of the most abundant beach-cast wrack, eelgrass (Zostera marina) (see Results), was studied under controlled conditions $\left(10^{\circ} \mathrm{C}-14^{\circ} \mathrm{C}\right.$; $10 \mathrm{~h} \mathrm{~L}: 14 \mathrm{~h} \mathrm{D})$ in a swimming pool $\left(336 \times 193 \times 56 \mathrm{~cm}^{3}\right)$. The bottom of the pool was covered with washed sand of different depth; thus, part of the pool area was covered by sea water, while the other part only contained wet sand. Either intact blades (2 per replicate) or the same amount of blade fragments $\left(5 \mathrm{~mm}^{2}\right)$ were added to plastic containers $\left(10 \times 18 \mathrm{~cm}^{2}\right)$ with perforated bottoms to ensure contact with the sea water environment. Boxes were either placed on the wet sand or into the sea water; a third treatment contained wet sand into which the wrack was buried. Each of these 6 treatments was replicated 12 times.

To start the experiment, all treatments were inoculated with filtered (500 $\mu \mathrm{m}$ pore size) seawater that had previously been preconditioned with beach-cast wrack for $8 \mathrm{~d}$ and then filtered again. The water in the pool was refreshed every $14 \mathrm{~d}$, and a circulating pump and two membrane pumps kept the water in move and aerated. The experiment was run for 12 weeks. Eelgrass blades were weighed before and after the experiment (dry weight, $60^{\circ} \mathrm{C}$ for $48 \mathrm{~h}$ ) so that mass loss could be calculated.

As a measure of microbial activity that caused the wrack mass loss, dehydrogenase activity was determined according to [13]. In brief, one half of a fresh sample (prior to oven-drying) was weighed and then homogenized in $2 \mathrm{~mL} \mathrm{1 \%} \mathrm{Tri-phenyl-tetrazoliumchlorid} \mathrm{(TTC)} \mathrm{and} \mathrm{shaken} \mathrm{for} 18$ hours in the dark at $20^{\circ} \mathrm{C}$. The reaction was stopped, and the dehydrogenated product of TTC, triphenolformazan (TPF), extracted through adding $4 \mathrm{~mL}$ acetone and shaking. After centrifugation at $4000 \mathrm{rpm}$ for 7 minutes and diluting $200 \mu \mathrm{L}$ of the supernatant in 
$1800 \mu \mathrm{L}$ acetone, TPF was photometrically quantified at $485 \mathrm{~nm}$.

\subsection{Statistics}

All graphical and statistical analyses were performed with SigmaPlot 10 (Systat Software Inc., San Jose, USA) and SPSS for Windows 15.0 (SPSS Inc., Chicago, USA).

Since most data did not meet the requirements of normal distribution, non-parametric-tests were used for analyses. For more than two independent samples, Kruskal-Wallace $\mathrm{H}$ tests (non-parametric equivalent of the one-way ANOVA) were conducted. In the cases of $\mathrm{p}<0.05$, Mann-Whitney $\mathrm{U}$ tests were used to find significant differences among samples.

\section{Results}

During our study, a total of at least 17 animal species were found in and underneath beach-cast wrack patches, and vegetal wrack comprised a total of 18 species (Table 1). However, a single patch normally consisted of not more than 7 to 8 plant and animal species. For both animal and vegetal species, abundances fluctuated widely over the year. Overall, the eelgrass Zostera marina was the most common detrital species, making up up to 99\% of wrack mass during fall and winter, although red and green algae together exceeded in biomass during spring and summer.

The Blue mussel Mytilus edulis (shells) was the most abundant animal species in beach-cast wrack. Carcinus maenas (Crustacea: Decapoda), Littorina littorea (Mollusca: Gastropoda), and Electra crustulenta (Bryozoa: Gymnolaemata) were present continuously but in much lower numbers. The beach flea, Orchestia gammarellus (Crustacea: Amphipoda), inhabits the sand underneath the drift line, and was frequently found in wrack patches.

The median amount of beach-cast wrack fluctuated over time from zero to $3000 \mathrm{~g} \cdot \mathrm{s}{ }^{-1}$ beach line (Figure 2), but also varied highly among replicates along the studied beach line. Although weeks 22 (end of May), 39 (end of September) and 49 (early December) provided significantly more wrack than the respective weeks before and after (Mann-Whitney U test: $\mathrm{p}<0.05$ ), there was no significant seasonal trend in wrack mass over the study period (trend analysis: $\mathrm{p}>0.3$ ). Along sampling transects, wrack was mostly found accumulated just above the waterline but might also have been transported landwards up to $15 \mathrm{~m}$ (Figure 3).

The spread of wrack patches from the water line into the upper supra-littoral (Figure 3) probably owed to remarkable fluctuations in water level over time (dotted line in Figure 3). After a time interval of little change in water level (weeks 18 - 42, early May to mid October), water level varied widely from week to week during winter and spring. The resulting variation in beach width by up to $30 \mathrm{~m}$ within just few days can be explained by the slope of the beach of 1:150 that remained stable throughout the entire study. Under these circumstances, even small changes in water level through wind-driven processes cause large differences in beach width in a no-tide system. Over the entire study period, we observed a trend towards wider beaches during winter than during summer and fall (trend analysis, $\mathrm{p}<0.05$ ).

Wind speed mostly ranged from 2 to $10 \mathrm{~m} \cdot \mathrm{s}^{-1}$, but sometimes reached $15 \mathrm{~m} \cdot \mathrm{s}^{-1}$. Strong storm events (> 25 $\mathrm{m} \cdot \mathrm{s}^{-1}$ ) were not recorded during our study. There was no significant correlation between the weekly amount of deposited wrack (white bars in Figure 4) and the mean wind speed during the previous week ( $>0.6)$,

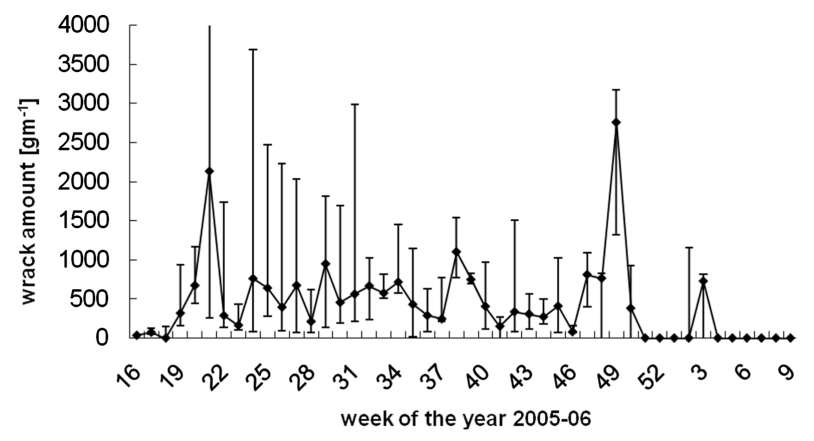

Figure 2. Weekly amount of beach-cast wrack during one year of collecting. Data are median \pm range of three weekly sampled replicates. 
Table 1. Plant and animal species in the beach-cast wrack during one year of observation.

\begin{tabular}{|c|c|c|c|}
\hline Animal species & & & Total amount $\left(\mathrm{g} / \mathbf{0 . 2 5} \mathrm{m}^{2}\right)$ \\
\hline Balanus balanus & Cirripedia & Crustacea & \\
\hline Carinus maenas & Malacostraca & Crustacea & \\
\hline Gammarus locusta & Malacostraca & Crustacea & \\
\hline Idotea balthica & Malacostraca & Crustacea & \\
\hline Orchestia gammarellus & Malacostraca & Crustacea & \\
\hline Pleurobrachia pileus & Tentaculifera & Ctenophora & \\
\hline Asterias rubens & Asteroidea & Echinodermata & \\
\hline Agelastica alni & Coleoptera & Insecta & \\
\hline Anatis ocellata & Coleoptera & Insecta & \\
\hline Fannidae & Diptera & Insecta & \\
\hline Staphylinidae & Coleoptera & Insecta & \\
\hline Cerastoderma edule & Bivalvia & Mollusca & \\
\hline Mya arenaia & Bivalvia & Mollusca & \\
\hline Mytilys edulis & Bivalvia & Mollusca & \\
\hline Littorina littorina & Gastropoda & Mollusca & \\
\hline Halichondria panicea & Demospongiae & Porifera & \\
\hline \multirow[t]{2}{*}{ Electra crustulenta } & Bryozoa & Tentaculata & \\
\hline & & & 608.11 \\
\hline \multicolumn{4}{|l|}{ Plant species } \\
\hline Fagus sylvatica & Fagaceae & Angiospermae & \\
\hline \multirow[t]{2}{*}{ Quercus rubor } & Fagaceae & Angiospermae & \\
\hline & & & 13.27 \\
\hline \multirow[t]{2}{*}{ Zostera marina } & Zosteraceae & Angiospermae & \\
\hline & & & 1024.25 \\
\hline Spongomorpha aeruginosa & Acrosiphoniaceae & Chlorophycota & \\
\hline Urospora penicilliformis & Acrosiphoniaceae & Chlorophycota & \\
\hline \multirow[t]{2}{*}{ Ulva sp. } & Ulvaceae & Chlorophycota & \\
\hline & & & 939.13 \\
\hline Pilayella littoralis & Ectocarpaceae & Phaeophycota & \\
\hline Fucus serratus & Fucaceae & Phaeophycota & \\
\hline Fucus serratus & Fucaceae & Phaeophycota & \\
\hline Fucus vesiculosus & Fucaceae & Phaeophycota & \\
\hline \multirow[t]{2}{*}{ Laminaria sp. } & Laminatiaceae & Phaeophycota & \\
\hline & & & 339.25 \\
\hline Porphyra sp. & Bangiaceae & Rhodophycota & \\
\hline Ceramium rubrum & Ceramiaceae & Rhodophycota & \\
\hline Delesseria sanguinea & Delesseriacea & Rhodophycota & \\
\hline Furcellaria lumbricalis & Furcellariacea & Rhodophycota & \\
\hline Chondrus cripus & Gigartinaceae & Rhodophycota & \\
\hline Coccotylus truncatus & Phullophoraceae & Rhodophycota & \\
\hline \multirow[t]{2}{*}{ Rhodomela confervoides } & Rhodomelaceae & Rhodophycota & \\
\hline & & & 975.51 \\
\hline
\end{tabular}




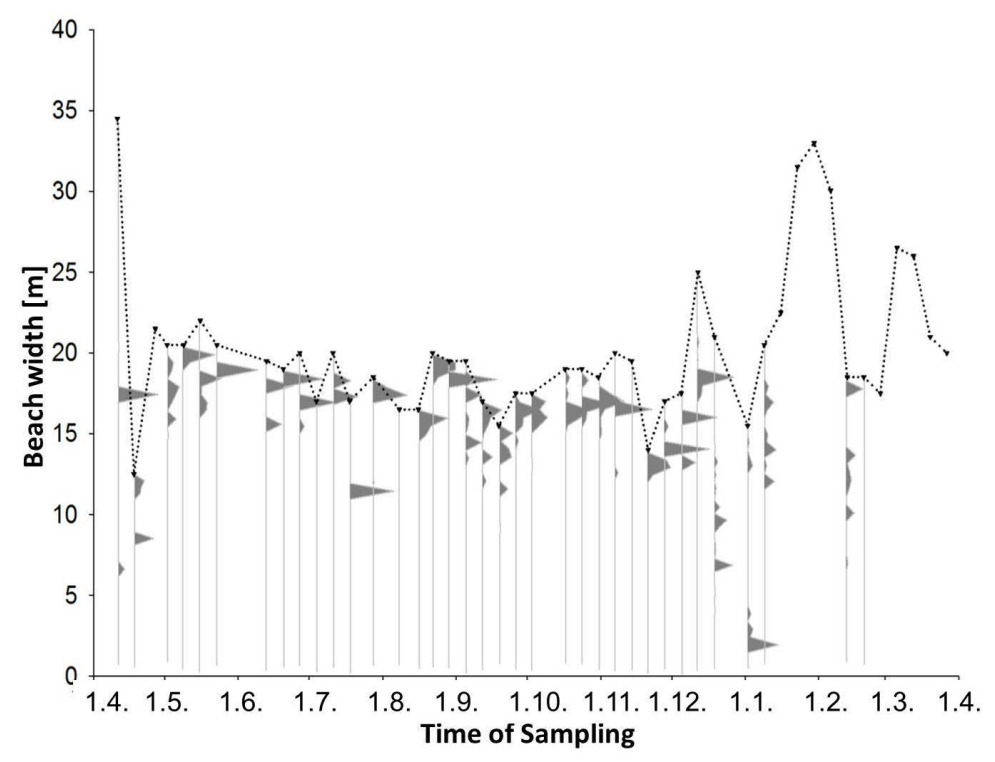

Figure 3. Beach width and wrack distribution along the sea-to-land gradient. Grey polygons represent percent of the total wrack amount sampled at one date within the weekly sampled transects; the dotted line represents the average beach width at that sampling date, with the upper part directing seaward, the lower part directing landward.

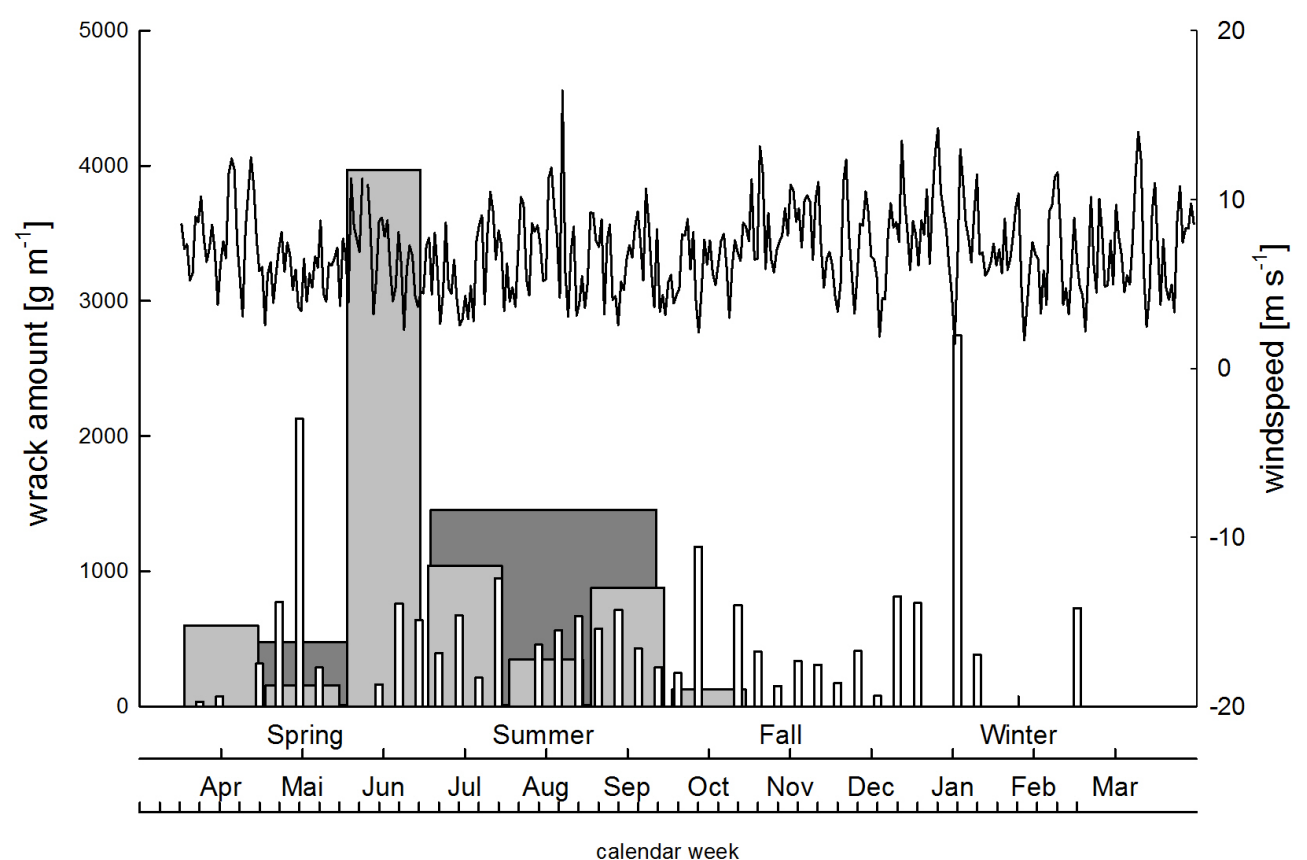

Figure 4. Wind speed (line) and weekly (white), monthly (light grey) and three-monthly (dark grey) amounts of beach-cast wrack over the time course of investigation.

although wind and wind-driven waves hit the beach at Bottsand almost exclusively from northern directions (white polygon in Figure 5), i.e. from the water front. Evidently, neither the weekly deposited wrack (white bars in Figure 4) does accumulate to build up the monthly sampled wrack masses (light grey bars in Figure 4), nor do wrack masses collected at three-month intervals (dark grey bars in Figure 4) reflect the amounts of wrack we sampled on a monthly basis. Thus, part of the beach-cast wrack is either re-suspended into coastal water upon extreme high water level events, or wrack patches are translocated landwards or along the shoreline by winds, 


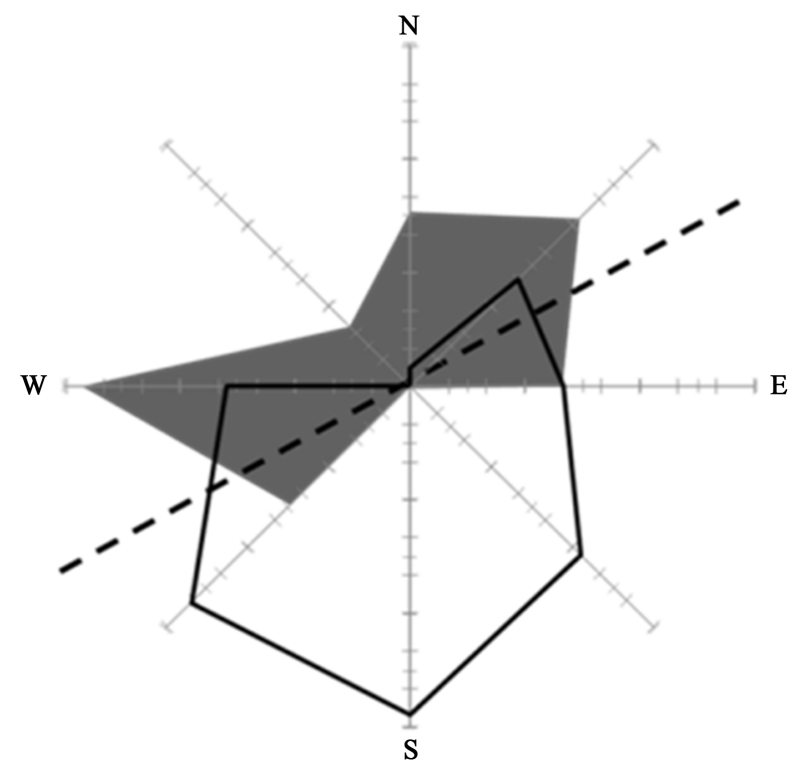

Figure 5. Proportion of predominating wind directions (white polygon with black outline) and direction of wrack transport (grey area) along the shore line (dashed line) through winddriven translocation.

resulting in strong spatio-temporal wrack dynamics ashore.

In this not tidally affected system, wind drift appears to explain the differences in wrack amounts collected weekly, monthly and three-monthly. Experimentally deposited mimics of eelgrass blades were heavily translocated (grey polygon in Figure 5) along the shoreline (dotted line in Figure 5). While this direction is perpendicular to the predominating wind direction, we propose that winds that hit the shore are re-directed by coastal dunes that separate the supra-littoral from the terrestrial realm. Thus, north winds turn into air currents towards southwest and northeast, coinciding with the shoreline and with the orientation of supra-littoral dunes.

Another process that directly contributes to wrack dynamics in the intertidal is wrack decay through weathering and microbes, as well as decomposition through the joint action of microbes and detritivores. In the present study, wrack eelgrass blades decayed through leaching and microbial activity at the same rate $(14 \%-22 \%$ per $14 \mathrm{~d}$ ) irrespective of whether the wrack was placed on the sand surface, was buried in sand (that in the field, thus, would not be translocated by wind or waves), or was re-suspended in water (Figure 6). Fragmentation of leaves, mimicking the action of macro-detritivores such as amphipods, resulted in increased decomposition rates only if wrack remained on the sand surface $(p<0.05)$ or was buried in sand $(p<0.1)$ (Figure 6). In coincidence, microbial (dehydrogenase) activity after $14 \mathrm{~d}$ of microbial decay did not differ among treatments with intact eelgrass blades (Figure 7), and fragmentation of eelgrass blades did significantly increase microbial activity only under water $(\mathrm{p}<0.05$; Figure 7$)$. Whereas, however, submerged eelgrass fragments were decomposed more slowly than fragments on top of, or buried in, sand ( $<0.05$; Figure 6 ), microbial activity on fragments did not differ among treatments (Figure 7).

\section{Discussion}

Despite the lack of tides in the Western Baltic Sea, the distribution of beach-cast wrack patches at Bottsand was highly dynamic. The only forces that can be taken responsible for causing spatio-temporal wrack dynamics are wind and wind-driven waves: marked short-term changes in water level, corresponding to both wind direction and speed and accompanied by high variation of beach width, demonstrate their strong influence on small-scale hydrology and topology ashore. Whereas tidally influenced beaches exhibit wrack dynamics within the time frame of twice-daily tides and lunar cycles (e.g., [4]), wind-driven changes in wrack distribution happen (1) more slowly, depending on weather conditions, and (2) less predictably. To this end, the place of wrack deposition entirely depends on the wind-controlled water level and varies unpredictably within days. By contrast, 


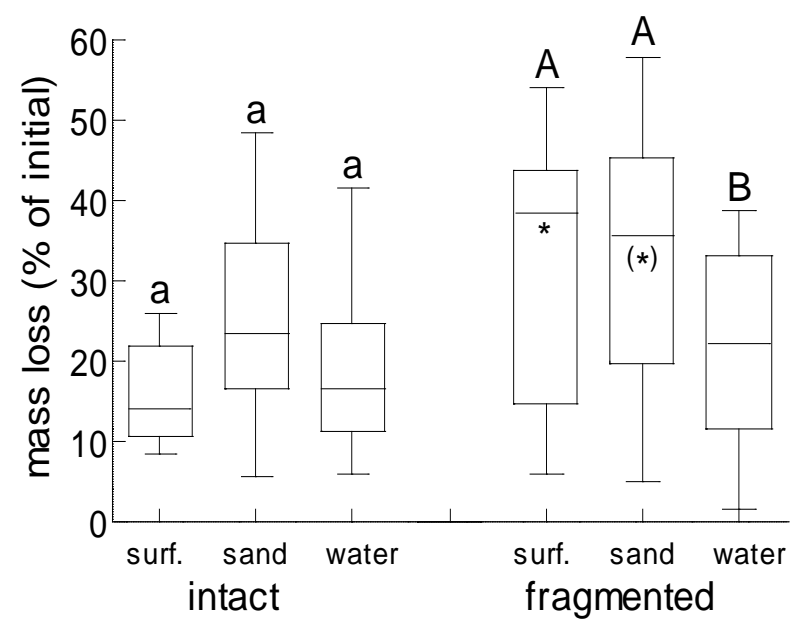

Figure 6. Wrack mass loss of intact versus fragmented eelgrass blades on the sand surface (surf.), buried in sand (sand), or under water (water); box plots represent minimum, $1^{\text {st }}$ quartile, median, $3^{\text {rd }}$ quartile and maximum $(\mathrm{N}=12)$; different lower and upper case letter indicate significant differences among treatments with intact and fragmented blades, respectively; asterisks indicate differences between fragmented and the corresponding intact blades $\left({ }^{*}: \mathrm{p}<0.05 ;\left(^{*}\right)\right.$ : $\mathrm{p}<0.1$ ).

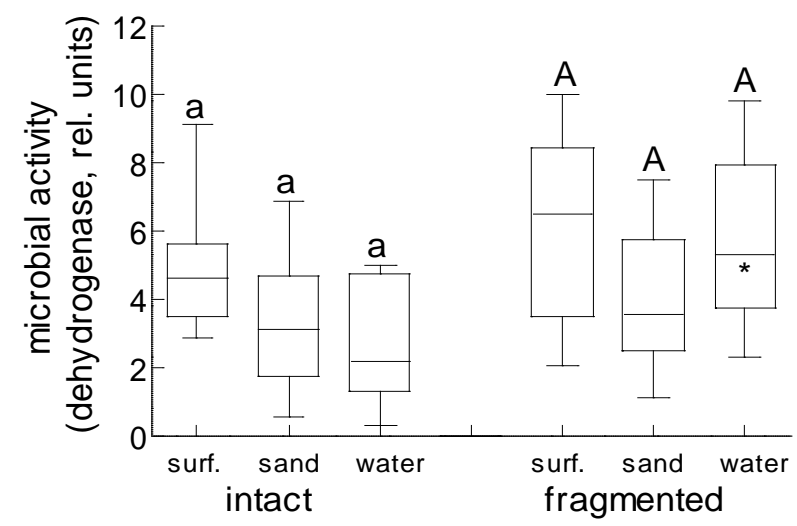

Figure 7. Microbial activity on intact versus fragmented eelgrass blades on the sand surface (surf.), buried in sand (sand), or under water (water); box plots represent minimum, $1^{\text {st }}$ quartile, median, $3^{\text {rd }}$ quartile and maximum $(\mathrm{N}=12)$; different lower and upper case letter indicate significant differences among treatments with intact and fragmented blades, respectively; asterisk indicates difference between fragmented and the corresponding intact blades $(\mathrm{p}<0.05)$.

wrack patches in tidal systems are deposited successively lower on the beach during the shift from spring to neap tides, resulting in a number of drift lines spreading along the shore direction that are re-suspended upon shift from neap to spring tide (c.f., [4]). As concluded from the present results, wrack patches in a tide-free system are re-suspended when the water level rises due to increasing wind speeds, resulting in decreasing beach width. Multiple drift lines build up upon distinctly decreasing wind speeds, resulting in decreasing water level and increasing beach width, and may remain in place until the next strong wind event, unless the wrack is translocated by the wind.

It remains an interesting question whether the amount of wrack deposited ashore differs between tidal and non-tidal system. The major predictors of the beach-cast wrack mass are wind and wave exposure (c.f., [4] [14]) 
and probably the amount of drift in coastal waters (c.f., [15] [16]) that, in turn, depends on the productivity and standing biomass of shallow-water macrophyte stands. Hence, we hold that sediment characteristics, nutrient content and other factors that affect macrophyte production rather than the presence or lack of tides control the amount of wrack that is deposited ashore for decomposition (see below). Nonetheless, there is a significant difference between beach types: on tidally influenced beaches, deposition of drifting wrack occurs upon outgoing ebb tide within the first ca 90 min after slack high tide [4]. By contrast, remarkable deposition in tide-free systems can only occur when the water level drops upon decreasing wind speed, resulting in increasing beach width, and indicating that the spatial distribution of wrack depends on the maxima of wind-controlled water level (see above). Thus, the amount of wrack ashore depends on the frequency and abruptness of changes in wind speed.

From this, taking into account the frequent and sometimes sudden changes in wind speed (and/or direction), we expect the amount of beach-cast wrack to be in a steady state. As has been shown by [4] on Canadian Pacific beaches, wrack does not necessarily remain on the beach until it is decomposed (see below) but may become resuspended upon submersion during high high tides. We found the same pattern in our tide-free study system: monthly collected amounts of beach-cast wrack were not the sum of weekly amounts, and the former did not accumulate to three-monthly amounts. Rather did the material accumulate to a maximum amount of ca 400 $\mathrm{g} \cdot \mathrm{m}^{-1}$ beach line within 2 - 3 weeks $\left[100\right.$ (sand beach) to 500 (gravel beach) $\mathrm{g} \cdot \mathrm{m}^{-1}$ within ca 1 week in a tidal system: [4])] after removal of all wrack (Figure 8).

Besides re-suspension of beach-cast wrack upon wind-driven rise of the water level, wind-driven drift along the shore line appears to have been significant in the present study. Although the predominant wind direction was northerly, wind-drift on average occurred predominantly along the W-E stretch of the beach. Probably, winds that hit the shore are re-directed by the supra-littoral sand dunes that separate the beach from the saltmarsh-covered berm at Bottsand along the beach stretch. Consequently, beach-cast wrack is translocated parallel to the beach stretch until caught by obstacles or dropped in wind-dead areas.

The major mechanism to prevent beach-cast wrack from drifting with beach-parallel winds probably is burying in the sand by wind and the beach infauna. However, the major macro-invertebrate beach inhabitant known to bury wrack through digging in the sand, beach fleas (here: Orchestia gammarellus), were rare at our study site (ca $800 \mathrm{~m}^{-2}$ : T. Horstkotte and M. Zimmer, unpubl.), as compared to densities of $>11,500 \mathrm{ind} \cdot \mathrm{m}^{-2}$ (Megalorchestia californiana) or $>16,500$ ind $\mathrm{m}^{-2}$ (Traskorchestia traskiana) on Canadian Pacific beaches [12] or even $>32,000$ ind. $\mathrm{m}^{-2}$ (Orchestia platensis) on northern New England (Atlantic) coasts [17]. Corroborating previous findings by [18], the low abundance of beach hoppers on Western Baltic sand and gravel beaches did not correlate with grain size of the beach substratum, but was best explained by the amount of beach-cast wrack (exponential regression: amphipod density $=9 \mathrm{e}^{0.04 \text { wrack mass }} \mathrm{R}^{2}=0.994$ ) (T. Horstkotte and M. Zimmer, unpubl.). To this end, the total mass of beach-cast wrack at our study site in Bottsand was comparably low (on average ca $400 \mathrm{~g} \cdot \mathrm{m}^{-1}$ after $2-3$ weeks), probably owing to the fact that it mostly consisted of eelgrass blades.

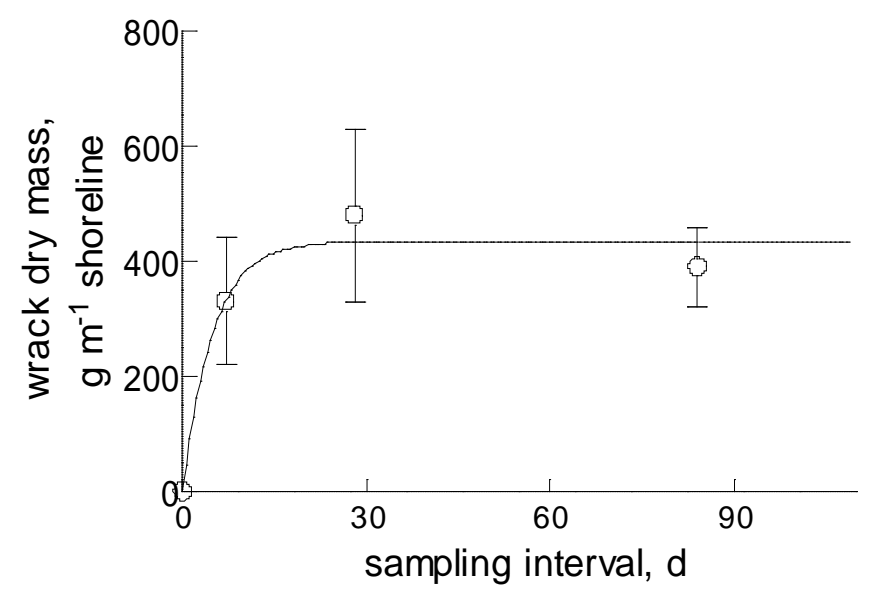

Figure 8. Accumulation of beach-cast wrack on the beach at Bottsand, with maximum load of ca $400 \mathrm{~g} \cdot \mathrm{m}^{-1}$ shore line as a result of wind-driven wrack dynamics. 
The predominance of eelgrass in the total amount of beach-cast wrack probably owes to beach-parallel currents in the shallow water off Bottsand [19] that do not allow for deposition of buoyant algal thalli ashore (c.f. [4]) but transport drift material further west. By contrast, extended patches of eelgrass in the shallow water off Bottsand (see Figure 1) produce large amounts of eelgrass that, particularly during fall senescence and storms, are washed ashore through waves, because of their limited buoyancy (c.f. [4]). Thus, the relatively little algal wrack that reaches the beach of Bottsand probably derives from algal stands (far) east of Bottsand, whereas eelgrass wrack stems from eelgrass beds in immediate vicinity.

Owing to species-specific decomposition rates of beach-cast wrack through the joint action of microbes and intertidal detritivores [5], drift lines exhibit marked changes in species composition upon aging [4]. Such change did not become obvious during our present study. Rather, eelgrass blades remained the most abundant wrack type (at the single-species level) throughout the year and even increased in relative significance during fall. Probably, the low density of detritivorous macro-invertebrates in our study system helps explain this observation: it is mostly microbial decay that breaks down beach-cast (eelgrass) wrack on Western Baltic beaches [20].

Whereas burying in the sand through biotic activity and fragmentation through shredding detritivores, wind and wave action will affect spatial dynamics of beach-cast wrack (see above), temporal dynamics through microbial decay were only marginally affected. Overall, wrack mass loss was significantly promoted by fragmentation (ANOVA: $\mathrm{p}=0.012$ ), whereas the position of the wrack only marginally affected mass loss (ANOVA: $\mathrm{p}$ $=0.085$ ). However, at the process scale, wrack mass loss through microbial decay was affected by fragmentation only on top of the sand. The differences in microbial activity on submerged fragments and intact blades were levelled out by the aquatic environment (c.f. [21]). Overall, decay on and in the sand tended to proceed faster than under water, indicating that detrital eelgrass matter at least in part will enter the semi-terrestrial area of the beach rather than being kept in the aquatic realm. Hence, we consider beach cast-wrack a significant spatial subsidy into the unproductive supra-littoral area of this sandy beach. To this end, the dynamics we observed here over the course of one year resemble those that had previously been described for tidal coast systems, irrespective of the fact that tidal influences are essentially missing at the coastline studied herein.

\section{Conclusion}

According to our study, the deposition of drifting wrack ashore provides a significant spatial subsidy to the unproductive supra-littoral area of this sandy beach. We propose that the amount of beach-cast wrack represents a steady-state of deposition versus re-suspension in the coastal water column and decomposition (Figure 9). The dynamics we observed here over the course of one year resemble those that had previously been described for tidal systems, irrespective of the fact that tidal influences are essentially missing at the coastline studied herein. However, additional studies are needed to be able to quantify fluxes of matter (i.e., nutrients and energy) between and within the water column and the littoral.

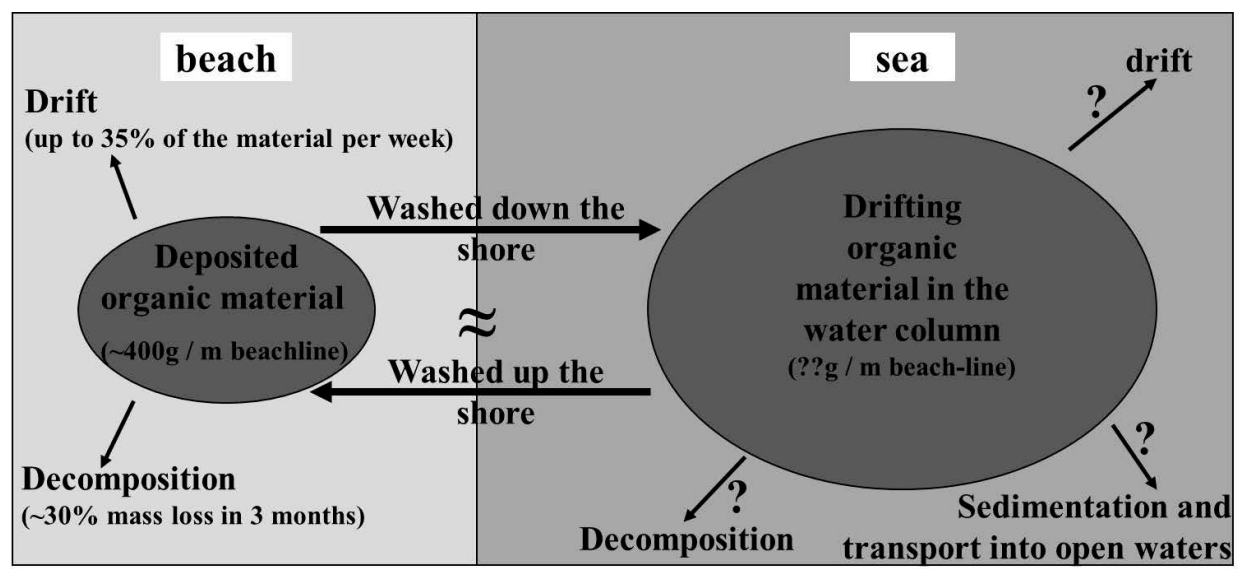

Figure 9. Conceptual scheme of matter (wrack) fluxes between coastal waters and the beach environment. Estimates are based on the data presented herein; question marks depict the need of further research for the quantification of matter fluxes. 


\section{Acknowledgements}

We thank Tony Fagerberg and Malte Treplin (geb. Mews) for valuable pre-experimental work in the lab and in the field during summer 2004.

\section{References}

[1] Norkko, J., Bonsdorff, E. and Norkko, A. (2000) Drifting Algal Mats as Alternative Habitat for Benthic Invertebrates: Species Specific Responses to a Transient Resource. Journal of Experimental Marine Biology and Ecology, 248, 79104. http://dx.doi.org/10.1016/S0022-0981(00)00155-6

[2] Pennings, S.C., Carefoot, T.H., Zimmer, M., Danko, J.P. and Ziegler, A. (2000) Feeding Preferences of Supralittoral Isopods and Amphipods. Canadian Journal of Zoology, 78, 1918-1929. http://dx.doi.org/10.1139/z00-143

[3] Colombini, I., Aloia, A., Fallaci, M., Pezzoli, G. and Chelazzi, L. (2000) Temporal and Spatial Use of Stranded Wrack by the Macrofauna of a Tropical Sandy Beach. Marine Biology, 136, 531-541. http://dx.doi.org/10.1007/s002270050713

[4] Orr, M., Zimmer, M., Mews, M. and Jelinski, D.E. (2005) Wrack Deposition on Different Beach Types: Spatial and Temporal Variation in the Pattern of Subsidy. Ecology, 86, 1496-1507. http://dx.doi.org/10.1890/04-1486

[5] Mews, M., Zimmer, M. and Jelinski, D.E. (2006) Species-Specific Decomposition Rates of Beach-Cast Wrack in Barkley Sound, British Columbia, Canada. Marine Ecology Progress Series, 328, 155-160. http://dx.doi.org/10.3354/meps328155

[6] Lewis, T.L., Mews, M., Jelinski, D.E. and Zimmer, M. (2007) Detrital Subsidy to the Supratidal Zone Provides Feeding Habitat for Intertidal Crabs. Estuaries and Coasts, 30, 451-458. http://dx.doi.org/10.1007/BF02819391

[7] Rodil, I., Olabarria, C., Lastra, M. and Lopez, J. (2008) Differential Effects of Native and Invasive Algal Wrack on Macrofaunal Assemblages Inhabiting Exposed Sandy Beaches. Journal of Experimental Marine Biology and Ecology, 358, 1-13. http://dx.doi.org/10.1016/j.jembe.2007.12.030

[8] Dolch, T. (2002) Die Auswirkungen der Wasserqualität auf den Tourismus am Beispiel des Oderästuars. Diplomarbeit, Geographisches Institut der Universität Bonn \& Institut für Ostseeforschung Warnemünde.

[9] Koerth, R. and Sterr, H. (2012) Ostseegemeinden im Klimawandel. RADOST-Berichtsreihe, 12, 1-20.

[10] Valiela, I., Collins, G., Kremer, J., Lajtha, K., Geist, M., Seely, B., Brawley, J. and Sham, C.H. (1997) Nitrogen Loading from Coastal Watersheds to Receiving Estuaries: New Method and Application. Ecological Applications, 7, 358380. http://dx.doi.org/10.1890/1051-0761(1997)007[0358:NLFCWT]2.0.CO;2

[11] Domínguez, H. and Belpaeme, K. (2006) Manual Beach Cleaning in Belgium: An Ecological Alternative. In: Tubielewicz, A., Ed., Living Marine Resources and Coastal Habitats, EuroCoast, Littoral, 131-135.

[12] Pelletier, A.J.D., Jelinski, D.E., Treplin, M. and Zimmer, M. (2011) Colonisation of Beach-Cast Macrophyte Wrack Patches by Talitrid Amphipods: A Primer. Estuaries \& Coasts, 34, 863-871. http://dx.doi.org/10.1007/s12237-011-9400-z

[13] Thalmann, A. (1968) Zur Methodik der Bestimmung der Dehydrogenaseaktivität im Boden mittels Triphenyltetrazoliumchlorid (TTC). Landwirtschaftliche Forschung, 21, 249-258.

[14] Milligan, K.L.D. and DeWreede, R.E. (2000) Variations in Holdfast Attachment Mechanics with Developmental Stage, Substratum-Type, Season, and Wave-Exposure for the Intertidal Kelp Species Hedophyllum sessile (C. Agardh) Setchell. Journal of Experimental Marine Biology and Ecology, 254, 189-209. http://dx.doi.org/10.1016/S0022-0981(00)00279-3

[15] Kirkman, H. and Kendrick, G.A. (1997) Ecological Significance and Commercial Harvesting of Drifting and BeachCast Macro-Algae and Seagrasses in Australia: A Review. Journal of Applied Phycology, 9, 311-326. http://dx.doi.org/10.1023/A:1007965506873

[16] Ochieng, C.A. and Erftemeijer, P.L.A. (1999) Accumulation of Seagrass Beach Cast along the Kenyan Coast: A Quantitative Assessment. Aquatic Botany, 65, 221-238. http://dx.doi.org/10.1016/S0304-3770(99)00042-X

[17] Behbehani, M. and Croker, R. (1982) Ecology of Beach Wrack in Northern New England with Special Reference to Orchestia platensis. Estuarine, Coastal and Shelf Science, 15, 611-620. http://dx.doi.org/10.1016/0272-7714(82)90075-0

[18] Ugolini, A., Felicioni, S., Ruffo, S. and Cipriani, L. (1995) Distribution of Talorchestia ugolinii and Other Sandhoppers in Corsica. Bolletino Zoologico, 62, 291-296. http://dx.doi.org/10.1080/11250009509356078

[19] Schrader, E. (1990) Dünenentwicklung im Raume des Bottsandes-Kieler Außenförde. Schriften des Naturwissenschaftlichen Vereins Schleswig-Holsteins, 60, 29-69.

[20] Jedrzejczak, M.F. (2002) Stranded Zostera marina L. vs Wrack Fauna Community Interactions on a Baltic Sandy 
Beach (Hel, Poland): A Short-Term Pilot Study. Part II. Driftline Effects of Succession Changes and Colonisation by Beach Fauna. Oceanologia, 44, 367-387.

[21] Treplin, M. and Zimmer, M. (2012) Drowned or Dry: A Cross-Habitat Comparison of Detrital Breakdown Processes. Ecosystems, 15, 477-491. http://dx.doi.org/10.1007/s10021-012-9523-5 